\title{
Identification of Photodegradation Products of DDT in Water
}

\author{
Jongki HoNG*, Jong-Shin Yoo*, Seung-Yong JunG** and Kang-Jin KIM**† \\ *Korea Basic Science Institute, 52 Eoun-dong, Tajeon, Korea \\ ** Department of Chemistry, Korea University, Anam-1, Seoul, Korea
}

\begin{abstract}
The photodegradation of DDT in water was examined with a high-pressure mercury lamp. A total of 17 photodegradation products of DDT including DDD, DDE and DDMU were identified by gas chromatography-mass spectrometry (GC-MS). Mass spectrometric analyses were done with electron impact (EI), methane positive chemical ionization (PCI) and electron capture negative ion chemical ionization (ENCI). The degradation rate of DDT in the presence of acetone was measured against the irradiation time. After the irradiation for $10 \mathrm{~min}, 80 \%$ of DDT was converted into a number of products, including DDD, DDE, DDMU and dichlorobenzophenone, through reductive dechlorination, oxidation, isomerization and chlorination. On the basis of the identified products, the photodegradation pathways of DDT are proposed.
\end{abstract}

Keywords DDT, photolysis, photodegradation product, structural identification, gas chromatography-mass spectrometry, photodegradation pathway

As the production of 1,1-bis(4-chlorophenyl)-2,2,2trichloroethane (DDT) had increased exponentially during 1940-1970's, it is obvious that its contamination of the environment has become a major issue in environmental protection. Although the use of DDT has been banned in developed countries, tropical countries still cling to the use of DDT because it is cheap and effective. ${ }^{1}$ As a result, DDT may still be found in many parts of the world. For instance, residue levels varying from a few nanograms per liter to micrograms in water ${ }^{2,3}$ and in fish $^{4}$ have been detected. The widespread use of DDT has led to a worldwide contamination of the food chain with this pesticide and its two major degradation products, 2,2-bis(4-chlorophenyl)-1,1-dichloroethane (DDD) and 2,2-bis(4-chlorophenyl)-1,1dichloroethylene (DDE).

Numerous studies on the photochemical transformation of DDT in organic solvents have been reported. ${ }^{5-9}$ It is known that DDT in organic solvents is mainly converted by photolysis into DDE, DDD and 2,2-bis(4chlorophenyl)-1-chloroethylene (DDMU) through reductive dechlorination mechanism. Fleck ${ }^{10}$ reported that DDT in ethanol was photolytically decomposed to 4,4'-dichlorobenzophenone (DCBP) in the presence of air. Although it is important to study the phototransformation of DDT in water since DDT and its photolytical products are detected in aquatic environment, there is relatively little information available in the literature on the photolysis of DDT in water due mainly to its low solubility. Most of the studies for iden-

$\dagger$ To whom correspondence should be addressed. tification of DDT and its derivatives have been conducted by using only mass spectrometry. ${ }^{11-15}$ Furthermore, efforts to find new photolysis products of DDT in water are limited.

The object of this study was to examine the photodegradation of DDT in water. The photodegradation products of DDT were identified by using gas chromatography-mass spectrometry with electron impact (EI), methane positive chemical ionization (PCI) and electron capture negative ion chemical ionization (ENCI). The chromatographic results for the photodegradation products and DDT were also described. In addition, some reasonable photodegradation pathways of DDT were also proposed on the basis of products identified.

\section{Experimental}

\section{Chemicals}

DDT, DDD, and DDE were obtained from Chem Service (West Chester, PA, USA) and Polyscience (Merrimac, IL, USA). 4,4'-Dichlorobenzophenone (DCBP), 4-chloroacetophenone, and 4-chlorobenzoic acid were purchased from Aldrich (Milwaukee, WI, USA). Standard solutions in acetone were stored at $4^{\circ} \mathrm{C} . \mathrm{N}$ Methyl- $N$-trimethylsilyltrifluoroacetamide (MSTFA) used as a silylation reagent was obtained from Sigma Chemical (St. Louis, MO, USA). All solvents used were of residual pesticide grade. Purified water was obtained from Milli-Q system (Millipore, USA). 


\section{Synthesis of photolysis products}

DDMU was prepared by treating DDD with $0.8 \mathrm{M}$ $\mathrm{KOH}$ in propan-2-ol for $20 \mathrm{~min}$ at $50^{\circ} \mathrm{C}$. Under this reaction condition, $95 \%$ of DDD was found to be converted into DDMU on the basis of GC-MS analysis. Bis(4-chlorophenyl)methane (DCPM) and bis(4-chlorophenyl)methanol (DCPM-ol) were prepared from 4,4'-dichlorobenzophenone (DCBP) by treatment with $\mathrm{NaBH}_{4}$. These compounds were also characterized by GC-MS with EI and PCI.

\section{Irradiation experiments}

An aqueous solution of DDT $(5 \mathrm{mg} / 100 \mathrm{ml})$ was irradiated for $10 \mathrm{~min}$ with a high-pressure mercury lamp (Hanovia Photochemical Lamp, $1.2 \mathrm{~kW}$ ). An air-cooled quartz filter was used to select $254 \mathrm{~nm}$. Pentachloronitrobenzene as an internal standard $(2 \mathrm{mg} / 100 \mathrm{ml})$ in ethylacetate was added after irradiation, and then the reaction mixture was extracted twice with $50 \mathrm{ml}$ of dichloromethane. The extracts in dichloromethane were passed through a $50 \mu \mathrm{m}$ Buchner funnel filled with $\mathrm{Na}_{2} \mathrm{SO}_{4}$ to remove trace water. The eluent was concentrated under a nitrogen stream, and the residue was dissolved with $5 \mathrm{ml}$ of ethylacetate. To derivatize the hydroxyl group of degradation products, MSTFA ( $2 \mathrm{ml}$ ) was added to the concentrated solution, followed by heating to $80^{\circ} \mathrm{C}$ for $15 \mathrm{~min}$. The resulting solution was injected onto GC-MS.

DDD, DDE and DDMU were independently irradiated under conditions identical to those used for DDT.

To study the effect of acetone as a photosensitizer on the rate of photodegradation, DDT was dissolved in $2 \%$, $5 \%$ and $10 \%$ aqueous acetone. The rate was directly measured at various intervals of time by gas chromatography-mass spectrometry (GC-MS). Quantitation of chromatographic peaks of major degradation products was carried out using their areas relative to the internal standard divided by the area of the starting material relative to the internal standard.

\section{Gas chromatography-mass spectrometry}

GC-MS data were collected on a Hewlett Packard 5890 GC and a JEOL SX-102A (Akishima, Tokyo, Japan) mass spectrometer equipped with a double focusing analyzer. A $30 \mathrm{~m} \times 0.25 \mathrm{~mm}$ i.d. fused silica capillary column coated with chemically bonded $5 \%$ phenyl-methylsilicone DB-5 (J\&W Scientific, Folsom, CA, USA) was used. The column temperature was programmed from $100^{\circ} \mathrm{C}$ held for $2 \mathrm{~min}$ to $300^{\circ} \mathrm{C}$ at $20^{\circ} \mathrm{C} / \mathrm{min}$. Samples were injected in the splitless mode. Carrier gas was helium (99.999\%) at $0.9 \mathrm{ml} / \mathrm{min}$ and inlet head pressure was $12 \mathrm{psig}$. Injector temperature was $270^{\circ} \mathrm{C}$.

Under EI conditions, ionization energy was $70 \mathrm{eV}$, ion source temperature was set at $200^{\circ} \mathrm{C}$ and scan range was 50-500 amu. Under PCI and ENCI conditions, methane $(99.99 \%)$ was used as the reagent gas, ion source temperature was $120^{\circ} \mathrm{C}$ and scan range was $100-$

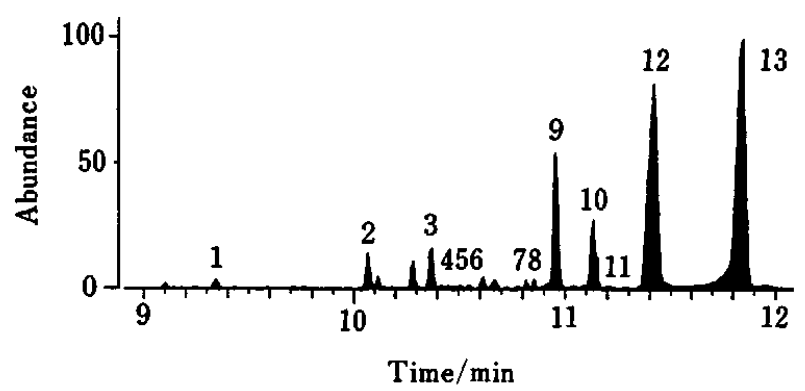

Fig. 1 Total ion chromatogram (TIC) of DDT's photodegradation products. The peaks' identification: 1 , p,p'-DCPM-ol; 2, 4,4'-DCBP; 3, o, p'-DDMU; 4, 2-(4chlorophenyl)-2-phenyl-1,1-dichloroethane; 5, p, $p^{\prime}$-DCPM; 6, 2,4,4'-TCBP; 7, 2,2-bis(4-chlorophenyl)-1-chloroethane; 8, 2,2-bis(4-chlorophenyl)ethylene; 9, o, $p^{\prime}$-DDE; 10, $p, p^{\prime}-$ $\mathrm{DDE} ; 11$, 3,6-dichloro-9-methylene fluorene; $12, p, p^{\prime}-$ DDMU and $p, p^{\prime}$-DDD; $13, p, p^{\prime}$-DDT.

$550 \mathrm{amu}$.

\section{Results and Discussion}

\section{Identification of DDT photodegradation products}

Figure 1 shows a typical total ion chromatogram obtained from the photolysis of DDT in water. As shown in Fig. 1, several photodegradation products were detected after 8 min irradiation. It was already reported that DDT in organic solution readily decomposed to DDD, DDE, DDMU and DCBP under the UV irradiation. ${ }^{8-10}$ Major photodegradation products such as DDD, DDE, DDMU and DCBP were also detected under the photolysis of DDT in water. It is interesting to observe that DDT was converted into isomeric photodegradation products such as $o, p^{\prime}$-DDE, $p, p^{\prime}-$ DDE, $o, p^{\prime}$-DDMU and $p, p^{\prime}$-DDMU. Besides major photodegradation products, lower abundant products formed through oxidation, dechlorination, reduction and isomerization of DDT were also observed. These compounds were identified by comparing retention times and mass spectra with those of authentic standards.

Table 1 presents the retention times and characteristic ions of major dechlorinated degradation products identified in this study. Due to the easy loss of $\mathrm{CCl}_{3}$ and $\mathrm{CHCl}_{2}$ from DDT and DDD, respectively, their EI-mass spectra showed weak intensity of the molecular ion cluster, but consisted almost exclusively of the $\mathrm{m} / \mathrm{z} 235$ ion cluster. For DDE and DDMU which contain a double bond between $\alpha$ - and $\beta$-carbons, EI-mass spectra showed abundant molecular ion clusters and the respective $\left(\mathrm{M}-\mathrm{Cl}_{2}\right)^{+}$ion cluster as the base peak. These mass spectral fragmentation patterns of DDT and its derivatives will be helpful for the identification of other degradation products in this study.

PCI and ENCI mass spectra of these compounds have been extensively reported by several groups. ${ }^{11-13}$ Their 
Table 1 Retention times (RT) and characteristic ions of DDT and major dechlorinated degradation products formed from the photolysis of DDT in water

\begin{tabular}{|c|c|c|c|c|c|c|c|}
\hline \multirow{2}{*}{ Compound } & \multirow{2}{*}{ M.W. } & \multirow{2}{*}{$\mathrm{RT} / \mathrm{min}$} & \multirow{2}{*}{$m / z$} & \multirow{2}{*}{ Ion } & \multicolumn{3}{|c|}{ Relative abundance, $\%$} \\
\hline & & & & & EI & PCI & ENCI \\
\hline \multirow[t]{4}{*}{$o, p^{\prime}$-DDMU } & 282 & 10.37 & 282 & {$[\mathrm{M}]^{+}$} & 74 & 58 & 100 \\
\hline & & & 247 & {$[\mathrm{M}-\mathrm{Cl}]^{+}$and $[\mathrm{M}-\mathrm{Cl}]^{-}$} & 29 & 100 & 35 \\
\hline & & & 212 & {$\left[\mathrm{M}-\mathrm{Cl}_{2}\right]^{+}$and $\left[\mathrm{M}-\mathrm{Cl}_{2}\right]^{-}$} & 100 & 14 & 22 \\
\hline & & & 176 & {$\left[\mathrm{M}-\mathrm{Cl}_{2}-\mathrm{HCl}^{+}\right.$} & 31 & 4 & \\
\hline \multirow[t]{5}{*}{$p, p^{\prime}-\mathrm{DDMU}$} & 282 & 10.62 & 282 & {$[\mathrm{M}]^{+}$and $[\mathrm{M}]^{-}$} & 75 & 57 & 100 \\
\hline & & & 247 & {$[\mathrm{M}-\mathrm{Cl}]^{+}$and $[\mathrm{M}-\mathrm{Cl}]^{-}$} & 30 & 100 & 43 \\
\hline & & & 212 & {$\left[\mathrm{M}-\mathrm{Cl}_{2}\right]^{+}$} & 100 & 13 & \\
\hline & & & 211 & {$\left[\mathrm{M}-\mathrm{Cl}-\mathrm{HCl}^{-}\right.$} & & & 11 \\
\hline & & & 176 & {$\left[\mathrm{M}-\mathrm{Cl}_{2}-\mathrm{HCl}\right]^{+}$} & 30 & & \\
\hline \multirow[t]{6}{*}{$o, p^{\prime}-\mathrm{DDE}$} & 316 & 10.94 & 316 & {$[\mathrm{M}]^{+}$and $[\mathrm{M}]^{-}$} & 50 & & 59 \\
\hline & & & 319 & {$[\mathrm{M}+\mathrm{H}+2]^{+}$} & & 100 & \\
\hline & & & 281 & {$[\mathrm{M}-\mathrm{Cl}]^{+}$and $[\mathrm{M}-\mathrm{Cl}]^{-}$} & & 52 & 21 \\
\hline & & & 246 & {$\left[\mathrm{M}-\mathrm{Cl}_{2}\right]^{+}$and $\left[\mathrm{M}-\mathrm{Cl}_{2}\right]^{-}$} & 100 & & 100 \\
\hline & & & 210 & {$\left[\mathrm{M}-\mathrm{Cl}_{2}-\mathrm{HCl}\right]^{+}$} & 25 & & \\
\hline & & & 176 & {$\left[\mathrm{M}-\mathrm{Cl}_{4}\right]^{+}$} & 25 & & \\
\hline \multirow[t]{7}{*}{$p, p^{\prime}$-DDE } & 316 & 11.12 & 316 & {$[\mathrm{M}]^{+}$} & 57 & & \\
\hline & & & 318 & {$[\mathrm{M}+2]$} & & & 100 \\
\hline & & & 319 & {$[\mathrm{M}+\mathrm{H}+2]^{+}$} & & 100 & \\
\hline & & & 281 & {$[\mathrm{M}-\mathrm{Cl}]^{+}$and $[\mathrm{M}-\mathrm{Cl}]^{-}$} & & 49 & 18 \\
\hline & & & 246 & {$\left[\mathrm{M}-\mathrm{Cl}_{2}\right]^{+}$} & 100 & & \\
\hline & & & 210 & {$\left[\mathrm{M}-\mathrm{Cl}_{2}-\mathrm{HCl}\right]^{+}$} & 28 & & \\
\hline & & & 176 & {$\left[\mathrm{M}-\mathrm{Cl}_{4}\right]^{+}$} & 25 & & \\
\hline \multirow[t]{8}{*}{$p, p^{\prime}$-DDD } & 318 & 11.45 & 318 & {$[\mathrm{M}]^{+}$and $[\mathrm{M}]^{-}$} & 9 & & 9 \\
\hline & & & 319 & {$[\mathrm{M}+\mathrm{H}]^{+}$} & & 18 & \\
\hline & & & 283 & {$[\mathrm{M}-\mathrm{Cl}]^{+}$} & & 71 & \\
\hline & & & 282 & {$\left[\mathrm{M}-\mathrm{HCl}^{-}\right.$} & & & 39 \\
\hline & & & 248 & {$\left[\mathrm{M}-\mathrm{Cl}_{2}\right]^{-}$} & & & 100 \\
\hline & & & 235 & {$\left[\mathrm{M}-\mathrm{CHCl}_{2}\right]^{+}$} & 100 & 52 & \\
\hline & & & 207 & {$\left[\mathrm{M}-\mathrm{phCl}^{+}\right.$} & & 100 & \\
\hline & & & 165 & {$\left[\mathrm{M}-\mathrm{CHCl}_{2}-\mathrm{Cl}_{2}\right]^{+}$} & 55 & & \\
\hline \multirow[t]{9}{*}{$p, p^{\prime}$-DDT } & 352 & 11.80 & 352 & {$[\mathrm{M}]^{+}$and $[\mathrm{M}]^{-}$} & 8 & & 3 \\
\hline & & & 353 & {$[\mathbf{M}+\mathbf{H}]^{+}$} & & 12 & \\
\hline & & & 317 & {$[\mathrm{M}-\mathrm{Cl}]^{+}$} & & 55 & \\
\hline & & & 316 & {$\left[\mathrm{M}-\mathrm{HCl}^{-}\right.$} & & & 97 \\
\hline & & & 281 & {$[\mathrm{M}-\mathrm{HCl}-\mathrm{Cl}]^{-}$} & & & 100 \\
\hline & & & 282 & {$\left[\mathrm{M}-\mathrm{Cl}_{2}\right]^{+}$} & 11 & & \\
\hline & & & 243 & {$[\mathrm{M}-\mathrm{phCl}+2]^{+}$} & & 100 & \\
\hline & & & 235 & {$\left[\mathrm{M}-\mathrm{CCl}_{3}\right]^{+}$} & 100 & & \\
\hline & & & 165 & {$\left[\mathrm{M}-\mathrm{CCl}_{3}-\mathrm{Cl}_{2}\right]^{+}$} & 38 & & \\
\hline
\end{tabular}

PCI mass spectra are almost consistent with our results. In PCI-mass spectra of DDD and DDT, the $(\mathrm{M}+\mathrm{H})^{+}$ion cluster appeared with about $10-20 \%$ of intensity relative to the base peak whereas $(\mathrm{M}-\mathrm{phCl})^{+}$ion clusters appeared as the respective base peak. A different mode of fragmentation was observed in ENCI mass spectra of DDT and DDD; molecular ion clusters have low abundances, and $(\mathrm{M}-\mathrm{HCl}-\mathrm{Cl})^{-}$and $\left(\mathrm{M}-\mathrm{Cl}_{2}\right)^{-}$ions are very abundant.

Besides major reductive dechlorinated products, several minor reductive products were also observed. Table 2 presents their retention times and characteristic ions. The EI-mass spectrum of M1 showed a molecular ion at $\mathrm{m} / \mathrm{z} 236$ within an ion cluster of a dichlorocompound. The molecular ion of M1 was confirmed by PCI. The retention time and mass spectrum of M1 were identical to those of bis(4-chlorophenyl)methane (DCPM) prepared in our laboratory. M2 showed the weak molecular ion at $m / z 284$ containing three chlorine atoms and the base peak $(\mathrm{M}-83)^{+}$at $m / z 201$ containing one chlorine atom. It is likely that this compound has the $\alpha$ - and $\beta$-saturated carbon chain, judged from the weak molecular ion like DDT or DDD, and the base peak $(\mathrm{M}-83)^{+}$was formed from the loss of $\mathrm{CHCl}_{2}$ to produce the stable benzylic cation. So M2 could be assigned as 2-(4-chlorophenyl)-2-phenyl-1,1-dichloroethane. The EI-mass spectrum of M3 showed the same molecular ion as that of $\mathrm{M} 2, m / z 284$, but their fragmentation patterns were different. M3 had a base peak at $m / z 235$, together with characteristic ions at $m / z 199$ 
Table 2 Retention times and characteristic ions of minor dechlorinated degradation products formed from the photolysis of DDT in water

\begin{tabular}{|c|c|c|c|c|c|c|}
\hline \multirow{2}{*}{ Compound } & \multirow{2}{*}{ M.W. } & \multirow{2}{*}{$\mathrm{RT} / \mathrm{min}$} & \multirow{2}{*}{$m / z$} & \multirow{2}{*}{ Ion } & \multicolumn{2}{|c|}{ Relative abundance, $\%$} \\
\hline & & & & & EI & PCI \\
\hline \multirow[t]{5}{*}{ M1 } & 236 & 9.35 & 236 & {$[\mathrm{M}]^{+}$} & 47 & \\
\hline & & & 237 & {$[\mathrm{M}+\mathrm{H}]^{+}$} & & 58 \\
\hline & & & 201 & {$[\mathrm{M}-\mathrm{Cl}]^{+}$} & 100 & 33 \\
\hline & & & 165 & {$[\mathrm{M}-\mathrm{Cl}-\mathrm{HCl}]^{+}$} & 49 & 24 \\
\hline & & & 125 & {$[\mathrm{M}-\mathrm{phCl}]^{+}$} & & 100 \\
\hline \multirow[t]{6}{*}{ M2 } & 284 & 10.46 & 284 & {$[\mathrm{M}]^{+}$} & 9 & \\
\hline & & & 285 & {$[\mathrm{M}+\mathrm{H}]^{+}$} & & 12 \\
\hline & & & 249 & {$[\mathrm{M}-\mathrm{Cl}]^{+}$} & & 100 \\
\hline & & & 201 & {$\left[\mathrm{M}-\mathrm{CHCl}_{2}\right]^{+}$} & 100 & 93 \\
\hline & & & 173 & {$[\mathrm{M}-\mathrm{phCl}]^{+}$} & & 52 \\
\hline & & & 166 & {$\left[\mathrm{M}-\mathrm{CHCl}_{2}-\mathrm{Cl}\right]^{+}$} & 45 & \\
\hline \multirow[t]{7}{*}{ M3 } & 284 & 10.65 & 284 & {$[\mathrm{M}]^{+}$} & 13 & \\
\hline & & & 285 & {$[\mathbf{M}+\mathbf{H}]^{+}$} & & 36 \\
\hline & & & 249 & {$[\mathrm{M}-\mathrm{Cl}]^{+}$} & & 79 \\
\hline & & & 235 & {$\left[\mathrm{M}-\mathrm{CH}_{2} \mathrm{Cl}\right]^{+}$} & 100 & 57 \\
\hline & & & 199 & {$\left[\mathrm{M}-\mathrm{CH}_{2} \mathrm{Cl}-\mathrm{HCl}\right]^{+}$} & 15 & \\
\hline & & & 173 & {$\left[\mathrm{M}-\mathrm{phCl}^{+}\right.$} & & 100 \\
\hline & & & 165 & {$\left[\mathrm{M}-\mathrm{CH}_{2} \mathrm{Cl}-\mathrm{Cl}_{2}\right]^{+}$} & 37 & \\
\hline \multirow[t]{4}{*}{ M4 } & 248 & 10.97 & 248 & {$[\mathrm{M}]^{+}$} & 100 & \\
\hline & & & 249 & {$[\mathrm{M}+\mathrm{H}]^{+}$} & & 100 \\
\hline & & & 212 & {$\left[\mathrm{M}-\mathrm{HCl}^{+}\right.$} & 12 & \\
\hline & & & 178 & {$\left[\mathrm{M}-\mathrm{Cl}_{2}\right]^{+}$} & 57 & \\
\hline \multirow[t]{4}{*}{ M5 } & 246 & 11.24 & 246 & {$[\mathbf{M}]^{+}$} & 100 & \\
\hline & & & 247 & {$[\mathrm{M}+\mathrm{H}]^{+}$} & & 100 \\
\hline & & & 210 & {$[\mathrm{M}-\mathrm{HCl}]^{+}$} & 4 & \\
\hline & & & 176 & {$\left[\mathrm{M}-\mathrm{Cl}_{2}\right]^{+}$} & 37 & \\
\hline
\end{tabular}

M1, bis(4-chlorophenyl)methane; M2, 2-(4-chlorophenyl)-2-phenyl-1,1-dichloroethane; M3, 2,2-bis(4-chlorophenyl)1-chloroethane; M4, 2,2-bis(4-chlorophenyl)ethylene; M5, 3,6-dichloro-9-methylenefluorene.

and 165. The base peak at $m / z 235$ suggests that this compound contains a bis(4-chlorophenyl)methyne group. M3 was tentatively identified as 2,2-bis(4-chlorophenyl)-1-chloroethane. M3 could have been formed by the replacement of a chlorine atom by hydrogen in DDD to yield the reductive form. The EI-mass spectrum of M4 showed a molecular ion cluster containing two chlorine atoms at $m / z 248$, and exhibited a similar fragmentation pattern to DDE and DDMU, which contain a double bond between $\alpha$ - and $\beta$-carbons. On the basis of mass fragmentation patterns, the structure of M4 was determined to be a derivative of DDMU. This compound was identified as 2,2-bis(4-chlorophenyl)ethylene formed from the dechlorination of DDMU. Finally, another product observed on the photolysis of DDT was formed by the loss of two hydrogen radicals from benzene rings in M4 to yield a cyclic compound. This compound was tentatively assigned as 3,6-dichloro9-methylenefluorene. A product similar to M5 was also observed as a photodegradation product of DDE in cyclohexane by Lepine et al. ${ }^{9}$ The molecular ion was observed as the base peak, due to its rigid cyclic structure.

In PCI mode, M2 and M3, which contain an $\alpha$ - and $\beta$ saturated carbon chain, showed fragment patterns similar to that of DDD while compounds containing unsaturated carbon chains such as M1, M4 and M5 produced strong and abundant molecular ions.

Oxidation was confirmed to be a minor photolytical decomposition route for DDT in water. Several oxidative degradation products including DCBP were detected; their retention times and mass spectral data are summarized in Table 3. However, since all these compounds listed in Table 3 were present at very low concentration, the organic extract should be concentrated to identify them by GC-MS. These compounds could be assigned as 4-chlorobenzaldehyde, 4-chloroacetophenone (CAP), 4-chlorobenzophenone (CBP), 4,4'-dichlorobenzophenone (DCBP) and 2,4,4'-trichlorobenzophenone (TCBP) based upon the comparison of their retention times and mass spectra with authentic standards. Their EI spectra showed a strong abundant ion at $\mathrm{m} / \mathrm{z} 139$ as well as the molecular ions in their EI-spectra. This appearance of $\mathrm{m} / z 139$ suggests that the stable phenylacyl cation was produced by the induced cleavage with charge initiation at the oxygen of an acyl or a hydroxyl group. Thus the presence of this ion diagnostically indicates that oxidation of DDT has taken place on the benzylic position. In general, benzaldehydes produce characteristic $(\mathrm{M}-\mathrm{H})^{+}$and $(\mathrm{M}-\mathrm{CHO})^{+}$ions which are substantially stable. ${ }^{16}$ 4-Chlorobenzaldehyde showed a 
Table 3 Retention times and characteristic ions of oxidative degradation products formed from the photolysis of DDT in water

\begin{tabular}{|c|c|c|c|c|c|c|c|}
\hline \multirow{2}{*}{ Compound } & \multirow{2}{*}{ M.W. } & \multirow{2}{*}{$\mathrm{RT} / \mathrm{min}$} & \multirow{2}{*}{$m / z$} & \multirow{2}{*}{ Ion } & \multicolumn{3}{|c|}{ Relative abundance, $\%$} \\
\hline & & & & & EI & PCI & ENCI \\
\hline \multirow[t]{4}{*}{ 4-Chlorobenzaldehyde } & 140 & 5.06 & 139 & {$[\mathrm{M}-\mathrm{H}]^{+}$and $[\mathrm{M}-\mathrm{H}]^{-}$} & 100 & & 100 \\
\hline & & & 140 & {$[\mathrm{M}]^{+}$} & 68 & & \\
\hline & & & 141 & {$[\mathbf{M}+\mathbf{H}]^{+}$} & & 100 & \\
\hline & & & 111 & {$\left[\mathrm{M}-\mathrm{CHO}^{+}\right.$} & 45 & & \\
\hline \multirow[t]{4}{*}{ 4-Chloroacetophenone } & 154 & 5.85 & 154 & {$[\mathrm{M}]^{+}$and $[\mathrm{M}]^{-}$} & 34 & & 100 \\
\hline & & & 155 & {$[\mathrm{M}+\mathrm{H}]^{+}$} & & 100 & \\
\hline & & & 139 & {$\left[\mathrm{M}-\mathrm{CH}_{3}\right]^{+}$} & 100 & & \\
\hline & & & 111 & {$\left[\mathrm{M}-\mathrm{CH}_{3} \mathrm{CO}\right]^{+}$} & 38 & & \\
\hline \multirow[t]{4}{*}{ 4-Chlorobenzophenone } & 216 & 9.04 & 216 & {$[\mathrm{M}]^{+}$and $[\mathrm{M}]^{-}$} & 83 & & 100 \\
\hline & & & 217 & {$[\mathbf{M}+\mathbf{H}]^{+}$} & & 100 & \\
\hline & & & 139 & {$[\mathrm{M}-\mathrm{ph}]^{+}$} & 79 & & \\
\hline & & & 105 & {$[\mathrm{M}-\mathrm{phCl}]^{+}$} & 100 & 18 & \\
\hline \multirow[t]{4}{*}{ 4,4'-Dichlorobenzophenone } & 250 & 10.07 & 250 & {$[\mathrm{M}]^{+}$and $[\mathrm{M}]^{-}$} & 54 & & 100 \\
\hline & & & 251 & {$[\mathrm{M}+\mathrm{H}]^{+}$} & & 100 & \\
\hline & & & 215 & {$[\mathrm{M}-\mathrm{Cl}]^{+}$} & 15 & & \\
\hline & & & 139 & {$\left[\mathrm{M}-\mathrm{phCl}^{+}\right.$} & 100 & 22 & \\
\hline \multirow[t]{4}{*}{ 2,4,4'-Trichlorobenzophenone } & 284 & 10.55 & 284 & {$[\mathrm{M}]^{+}$and $[\mathrm{M}]^{-}$} & 57 & & 100 \\
\hline & & & 285 & {$[\mathrm{M}+\mathrm{H}]^{+}$} & & 100 & \\
\hline & & & 173 & {$\left[\mathrm{M}-\mathrm{phCl}^{+}\right.$} & 62 & & \\
\hline & & & 139 & {$\left[\mathrm{M}-\mathrm{phCl}_{2}\right]^{+}$} & 100 & & \\
\hline
\end{tabular}

Table 4 Retention times and characteristic ions of TMS derivatized hydroxylated degradation products formed from the photolysis of DDT in water

\begin{tabular}{|c|c|c|c|c|c|c|}
\hline \multirow[t]{2}{*}{ Compound } & \multirow[t]{2}{*}{ M.W. } & \multirow[t]{2}{*}{$\mathrm{RT} / \mathrm{min}$} & \multirow[t]{2}{*}{$m / z$} & \multirow[t]{2}{*}{ Ion } & \multicolumn{2}{|c|}{$\begin{array}{c}\text { Relative } \\
\text { abundance, } \\
\%\end{array}$} \\
\hline & & & & & EI & PCI \\
\hline \multirow[t]{3}{*}{ 4-Chlorobenzoic acid-OTMS } & 228 & 11.23 & 229 & {$[\mathbf{M}+\mathbf{H}]^{+}$} & & 100 \\
\hline & & & 213 & {$\left[\mathrm{M}-\mathrm{CH}_{3}\right]^{+}$} & 100 & \\
\hline & & & 139 & {$[\mathrm{M}-\mathrm{OTMS}]^{+}$} & 46 & 23 \\
\hline \multirow[t]{6}{*}{ 4-Chlorobenzhydrol-OTMS } & 290 & 14.92 & 291 & {$[\mathrm{M}+\mathrm{H}]^{+}$} & & 45 \\
\hline & & & 290 & {$[\mathrm{M}]^{+}$} & 24 & \\
\hline & & & 275 & {$\left[\mathrm{M}-\mathrm{CH}_{3}\right]^{+}$} & 13 & \\
\hline & & & 255 & {$[\mathrm{M}-\mathrm{Cl}]^{+}$} & 16 & \\
\hline & & & 201 & {$[\mathrm{M}-\mathrm{OTMS}]^{+}$} & 100 & 100 \\
\hline & & & 165 & {$[\mathrm{M}-\mathrm{OTMS}-\mathrm{HCl}]^{+}$} & 68 & \\
\hline \multirow[t]{5}{*}{ Bis(4-chlorophenyl)methanol-OTMS } & 324 & 16.42 & 325 & {$[\mathrm{M}+\mathrm{H}]^{+}$} & & 56 \\
\hline & & & 324 & {$[\mathrm{M}]^{+}$} & 17 & \\
\hline & & & 309 & {$\left[\mathrm{M}-\mathrm{CH}_{3}\right]^{+}$} & 21 & \\
\hline & & & 235 & {$[\mathrm{M}-\mathrm{OTMS}]^{+}$} & 100 & 100 \\
\hline & & & 165 & {$\left[\mathrm{M}-\mathrm{OTMS}-\mathrm{Cl}_{2}\right]^{+}$} & 62 & \\
\hline \multirow[t]{5}{*}{ 2,4-Dichlorophenyl-4'-chlorophenylmethanol-OTMS } & 358 & 17.14 & 359 & {$[\mathrm{M}+\mathrm{H}]^{+}$} & & 42 \\
\hline & & & 343 & {$\left[\mathrm{M}-\mathrm{CH}_{3}\right]^{+}$} & 55 & \\
\hline & & & 269 & {$[\mathrm{M}-\mathrm{OTMS}]^{+}$} & 100 & 100 \\
\hline & & & 233 & {$[\mathrm{M}-\mathrm{OTMS}-\mathrm{Cl}]^{+}$} & 21 & \\
\hline & & & 199 & {$[\mathrm{M}-\mathrm{OTMS}-\mathrm{HCl}-\mathrm{Cl}]^{+}$} & 68 & \\
\hline
\end{tabular}

strong intense $(\mathrm{M}-\mathrm{H})^{+}$ion in EI mode, whileas it showed exclusively an $(\mathrm{M}+\mathrm{H})^{+}$ion in PCI mode. The EI mass spectrum of TCBP which was tentatively assigned showed similar fragmentation patterns to those of CBP and DCBP.

Some of the degradation products which have a hydroxyl group produced a weak molecular ion in the EI mass spectra and exhibited poor sensitivity in the analysis 


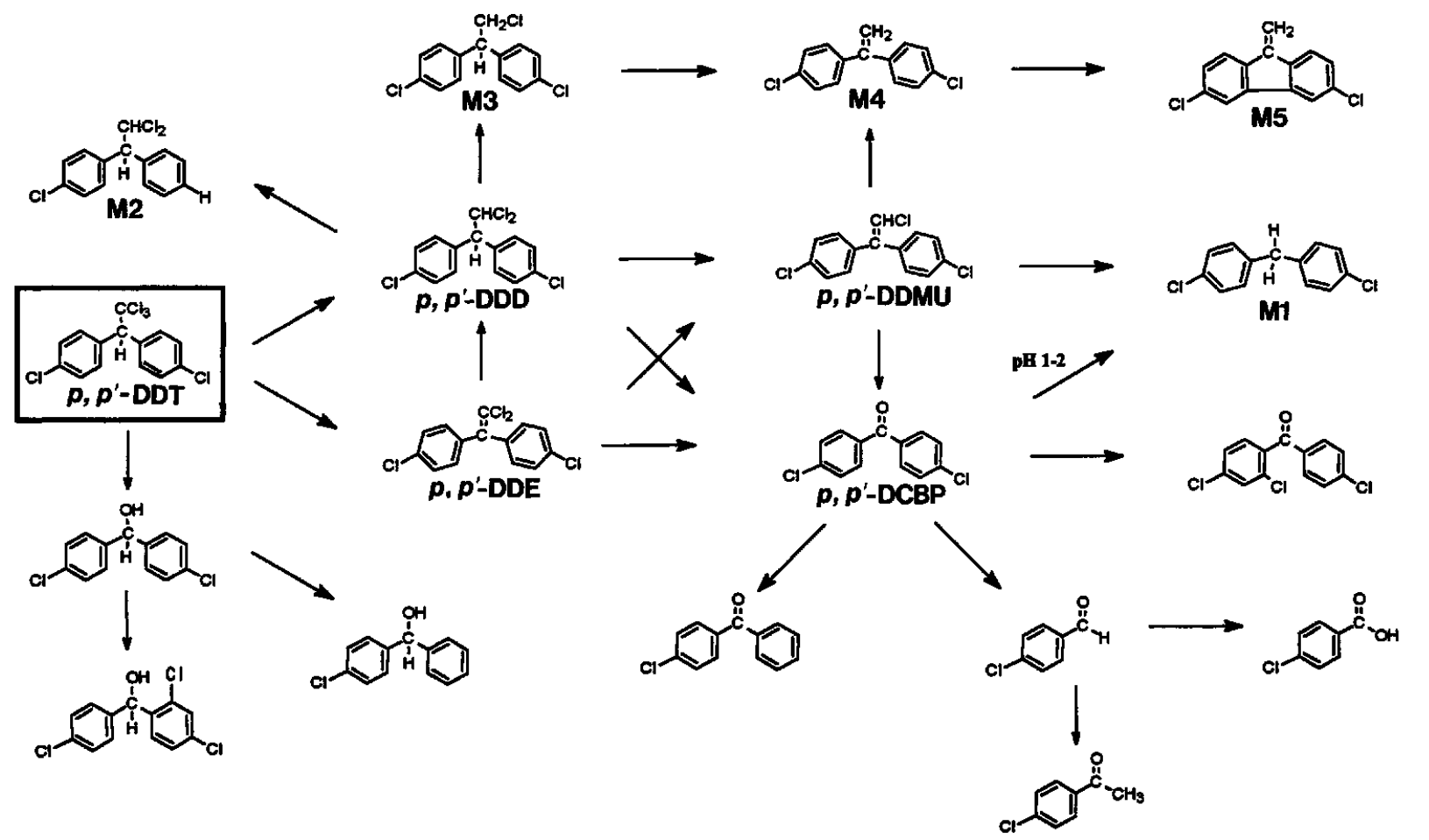

Fig. 2 Proposed photodegradation pathways of DDT in water.

by gas chromatography. Thus to identify hydroxylated degradation products of DDT, a trimethylsilylation (TMS) reaction was adopted to the organic extracts with MSTFA. Four hydroxylated degradation products were expected to yield through the TMS derivatization. They were 4-chlorobenzoic acid, 4-chlorobenzhydrol, bis(4-chlorophenyl)methanol, and 2,4-dichlorophenyl4'-chlorophenylmethanol. Among them, 4-chlorobenzoic acid and bis(4-chlorophenyl)methanol were easily confirmed by matching their retention times and mass spectra with those of standards. The retention times and characteristic ions of the TMS derivatized compounds from hydroxylated degradation products obtained by GC-MS with EI and PCI are listed in Table 4. They produced the molecular ion and $(\mathrm{M}-15)^{+}$ion in EI mode. The base peaks were produced by the inductive cleavage with charge initiation at oxygen of OTMS group, followed by removal of $\mathrm{C}_{6} \mathrm{H}_{4-x} \mathrm{Cl}_{x}$ (where $x=1$ or 2). Their molecular weights were also confirmed by PCI. Their PCI mass spectra showed that the base peak was formed by the loss of a $\left(\mathrm{CH}_{3}\right)_{3} \mathrm{SiOH}$ molecule, except for 4-chlorobenzoic acid. For TMS derivatized 4-chlorobenzoic acid, the protonated molecular ion was observed as the base peak.

\section{Photodegradation pathways of DDT}

The formation mechanism of DDD and DDE from DDT under photolytical conditions in organic solution was suggested by Mosier et al. ${ }^{5}$ A dechlorination reaction occurs first at the $\beta$-carbon of DDT to produce DDD. In this reaction, the radical produced by homo- lytical cleavage at the carbon-chlorine bond on the $\beta$ carbon is stabilized by two chlorines on the same carbon. During the photolysis of DDT, the production of $\mathrm{HCl}$ will continuously increase. Therefore, as the irradiation time increases, the acidity of reaction solution also increases. Although DDT disappearance and DDD formation were not dependent upon the $\mathrm{HCl}$ production $^{17}$, the formation of some of degradation products was influenced by $\mathrm{HCl}$ in the photo-reaction process.

Based on the identification of photodegradation products of DDT in water, its degradation pathways are proposed in Fig. 2. For the purpose of elucidating degradation pathways, irradiation of major degradation products such as DDD, DDE and DDMU and identification of the degradation products were independently carried out under the same experimental conditions. Irradiation of DDD produced significant amounts of DDMU and small amounts of other dechlorinated products, such as M1, M2, M3, M4 and M5, as shown in Fig. 2. One of the oxidative degradation products, DCBP, was also observed as a major degradation product of DDD. As indicated in Fig. 2, dechlorination of DDD mainly occurred at the $\beta$-chlorine, but the dechlorination product from an aromatic moiety, M2, was also observed as a minor one. M1 can be formed from the loss of the $\beta$ carbon of DDD through DDMU. M3 can be produced by the replacement of a $\beta$ chlorine by a hydrogen radical. M4 can be formed through two different pathways. The first involves the loss of $\mathrm{HCl}$ molecule from M3. The second involves the replacement of a $\beta$ chlorine by a hydrogen radical from DDMU. 
The formation of M5 must occur through the abstraction of two hydrogen radicals from each aromatic ring of M4, followed by the formation of a bond between the two aromatic rings.

Irradiation of DDE yielded DDMU and DCBP as major products, and DDD was present only in a trace amount. However, DDE formation was not observed under the irradiation of DDD. Apparently, this could explain that the abstraction of two hydrogen radicals or the loss of an $\mathrm{H}_{2}$ molecule in the $\alpha$ - and $\beta$-saturated carbon of DDD is not favorable to form DDE whereas the elimination of $\mathrm{HCl}$ is favorable to produce DDMU under irradiation of DDD.

Irradiation of DCBP in water did not produce DCPM (M1), suggesting that formation of DCPM from DCBP may depend on the $\mathrm{pH}$ of the reaction solution. Since DCBP has no $\beta$-chlorines, unlike DDT, DDD and DDE, the $\mathrm{pH}$ of the solution could not change to an acidic condition during the photodegradation reaction. When DCBP was irradiated at pH $1-2$ adjusted externally by the addition of HCl, DCPM and DCPM-ol could indeed be observed, albeit in a trace level. The formation of TCBP and CBP can be explained by the chlorination and dechlorination from DCBP, respectively. The detailed formation mechanism of 4-chloroacetophenone found from the degradation of DCBP is not clear at the present time. Further studies are required.

Judging from the observation of degradation pathways for DDT and its major degradation products, we found both DDD and DDE to be the direct precursors of DDMU and DCBP. DDD was the only precursor of M3 through the replacement of a $\beta$ chlorine with hydrogen. In particular, CBP and TCBP could be formed by the oxidative chlorination and reductive dechlorination, respectively, from DCBP. This result could explain how DCBP can absorb light and at the same time can transfer the absorbed energy to other molecules.

Acetone is known as a triplet-photosensitizer ${ }^{18,19}$ and is almost always present in the natural aquatic environment. When irradiation of DDT was performed in water in the presence of $5 \%$ acetone, the degradation rate of DDT increased by 1.5-2 times compared with that in the absence of acetone. With the increase of added acetone, the degradation rate exponentially increased. Prakash and coworkers ${ }^{20}$ reported that the photosensitizer induced photooxidation reactions by the generation of reactive oxygen species. A similar photooxidation reaction could probably explain the formation of DCBP and other oxidative products observed in the present study. Moreover, DCBP, which is a major degradation product of DDT, DDD and DDE, could also play an important part as a photosensitizer during irradiation of DDT.

In Fig. 3, the relative abundance of DDT and its major degradation products based on the integrated area relative to the internal standard are plotted against irradiation time. All data points are the average of three measurements. The degradation of DDT could ap-

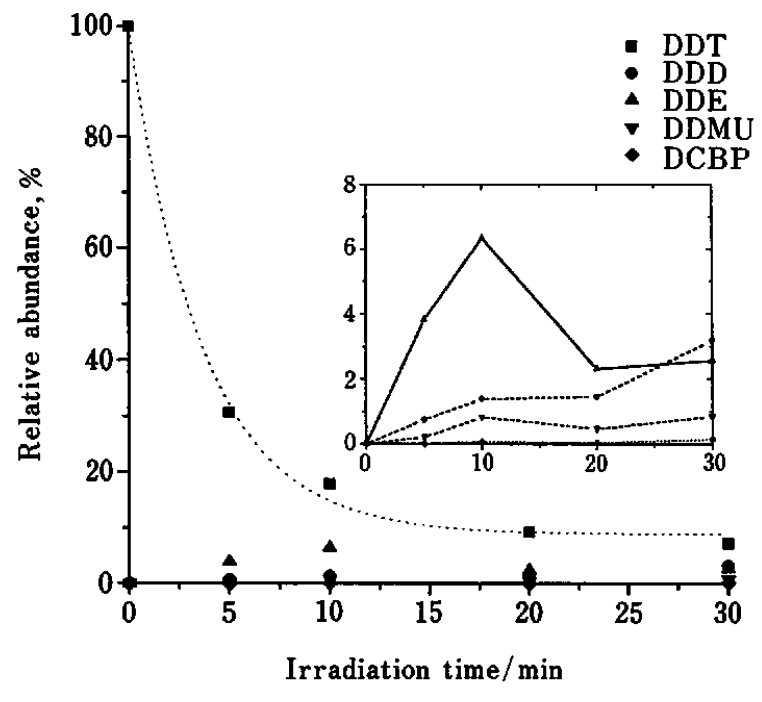

Fig. 3 Relative abundance of DDT photodegradation and formation of selected products in the presence of $5 \%$ acetone.

proximately be described by a first-order kinetics. As can be seen in Fig. 3, DDT degraded extremely rapid and the half-life $t_{1 / 2}=2.92 \mathrm{~min}$. DDE was formed much more rapidly than other degradation products. However, when the irradiation time is longer than $10 \mathrm{~min}$, DDE rapidly decayed. On the other hand, the formations of DDD, DCBP and DDMU were slow but their decay was not observed up to $30 \mathrm{~min}$ of the irradiation. This can support the result obtained by Mosier et al. ${ }^{5}$ that DDE showed higher quantum yield than DDD and DCBP.

The photolytical pathway of DDT in water was mainly reductive dechlorination in the $\alpha$ - and $\beta$-saturated alkyl chain, but it rarely occurred at the aryl position. On the other hand, chlorination was found on the aromatic ring; this was evident from the observation of TCBP and 2,4dichlorophenyl-4'-chlorophenylmethanol. Oxidation in the $\alpha$-carbon of DDT was also observed, but did not occur in the aryl position.

Although GC-MS with EI mode is a typical mode of confirmation for DDT and its photodegradation products, further confirmation by GC-MS with PCI and ENCI for photodegradation products is recommended. Chemical ionization method provided information about molecular weight and supplementary structural data to EI. The mass fragmentation patterns for DDT and its major products under EI, PCI and ENCI mode were greatly influenced by the degree of unsaturation in the $\alpha$ and $\beta$-carbon chain or the presence of an oxygen atom in the $\alpha$ carbon. The compounds with an unsaturated carbon chain gave simple spectra and produced strong abundant molecular ions, whereas ones with a saturated carbon chain produced weak molecular ions and exhibited diverse fragmentation patterns. The compounds that have a ketone or hydroxyl group in the $\alpha$ carbon produced a significantly diagnostic ion at $\mathrm{m} / \mathrm{z}$ 139 in both EI and PCI modes. Derivatization with 
MSTFA improved the gas chromatographic properties and therefore could be used to identify the hydroxylated products. The formation of OTMS derivatives affected the fragmentation patterns by producing more characteristic ions. The observation of mass fragmentation patterns could help to clarify the structures of minor degradation products in the photolysis of DDT in water.

This work was supported by the Korea Science and Engineering Foundation. (No. 94-1400-05-01-3)

\section{References}

1. S. J. Eisenreich, W. A. Willford and W. M. J. Strachan, in "Intermedia Pollutant Transport: Modelling and Field Measurements", ed., D. Allen, Plenum, New York, 1989.

2. A. G. Kelly, I. Cruz and D. E. Wells, Anal. Chim. Acta, 276, 3 (1993).

3. I. Cruz, D. E. Wells and I. L. Marr, Anal. Chim. Acta, 283, 280 (1993).

4. C. J. Schmitt, J. L. Zajicek and M. A. Ribik, Arch. Environ. Contam. Toxicol., 14, 225 (1985).

5. A. R. Mosier, W. D. Guenzi and L. L. Miller, Science [Washington, D. C.], 164, 1083 (1965).

6. L. L. Miller and R. S. Narang, Science [Washington, D. C.], 169, 368 (1970).

7. J. R. Plimmer, U. I. Klingebiel, B. E. Hummer, Science [Washington, D. C.], 167, 67 (1970).
8. F. L. Lepine, J. Agric. Food Chem., 39, 2112 (1991).

9. F. L. Lepine, F. Brochu, S. Milot, O. A. Mamer and Y. Pepin, J. Agric. Food. Chem., 42, 2012 (1994).

10. E. E. Fleck, J. Amer. Chem. Soc., 71, 1034 (1949).

11. NIST/EPA/NIH Mass Spectral Database, Ver. 4.0, U.S. Department of Commerce, Gaithersberg, 1992.

12. E. A. Stemmler and R. A. Hites, Anal. Chem., 60, 782 (1988).

13. F. L. Lepine, S. Milot and O. J. Mamer, Mass Spectrom., 30, 885 (1995).

14. R. C. Dougherty, J. D. Roberts and F. J. Biros, Anal. Chem., 47, 54 (1975).

15. E. A. Stemmler and R. A. Hites, "Electron Capture Negative Ion Mass Spectra of Environmental Contaminants and Related Compounds", VCH Publishers, New York, 1988.

16. F. W. McLafferty and F. Turecek, "Interpretation of Mass Spectra", 4th ed., p. 252, University Science Books, Mill Valley, 1993.

17. W. V. Sherman, R. Evans, E. Nesyto and C. Radlowski, Nature [London], 232, 118 (1971).

18. M. Jang and S. R. McDow, Environ. Sci. Technol., 29, 2654 (1995).

19. S. R. McDow, Q. R. Sun, M. Vartianinen, Y. S. Hong, Y. L. Yao, T. Fister, R. Q. Yao and R. M. Kamens, Environ. Sci. Technol., 28, 2147 (1994).

20. S. Prakash, G. S. Tandon, T. D. Seth and P. C. Joshi, Biochem. Biophys. Res. Commun., 199, 1284 (1994).

(Received September 3, 1996) (Accepted October 30, 1996) 